- Describes inequalities in the availability of NHS dental practitioners between Scottish Health Boards.

- Demonstrates how simple dentist-population ratios may overestimate the availability of NHS dental practitioners in a Health Board area by more than $100 \%$.

- Outlines a useful method for re-modelling dentist-population ratios to account for part-time working, provision of private services and variation in service productivity.

\title{
Access to dental services in Scotland: an analysis of dentist-population ratios
}

\author{
J. T. Newton, ${ }^{1}$ A. C. Williams ${ }^{2}$ and E. J. Bower ${ }^{3}$
}

\begin{abstract}
Objective To assess inequalities in the availability of NHS dental services between Health Boards in Scotland.
\end{abstract}

Study design Postal questionnaire survey of all dentists $(n=2,852)$ registered with the General Dental Council at an address in Scotland. Methods Data obtained on NHS working hours were used to model dentist to population (D/P) ratios and primary care $D / P$ ratios corrected for part time working, variation in service productivity and the provision of private services.

Results A total of 2,134 completed questionnaires (74.8\%) were received. There was a wide variation in $D / P$ ratios between Health Boards. Dumfries \&t Galloway and Grampian had the lowest, and Tayside and Greater Glasgow the highest D/P ratios, irrespective of method of calculation. The corrected D/P ratios for the other Health Boards were more similar than was suggested by the simple ratios of registered dentists to population size.

Conclusions There was considerable variation in the availability of NHS dental practitioners between Health Boards. Simple ratios of registered dentists to population size can mask the true availability of specific dental services such as NHS dental care.

\section{INTRODUCTION}

Access to dental health services has received much attention in the recent past both in the United Kingdom and internationally. ${ }^{1,2}$ Within Scotland, plans to improve access to dental services are outlined in An action plan for improving oral health and modernising NHS dental services in Scotland. ${ }^{3}$ The proposals include an increase in the number of dentists and dental care professionals in training and changes in the way in which

\footnotetext{
${ }^{1}$ Professor of Psychology as Applied to Dentistry, ${ }^{2}$ Consultant in Orthodontics, ${ }^{{ }^{*}} \mathrm{Clini}-$ cal Research Assistant, Department of Oral Health Services Research and Dental Public Health, King's College London Dental Institute, Caldecot Road, London, SE5 9RW ${ }^{*}$ Correspondence to: Dr Elizabeth J. Bower

Email: elizabeth.bower@kcl.ac.uk
}

Online article number E6

Refereed Paper - accepted 20 March 2007

DOI: 10.1038/bdj.2007.1107

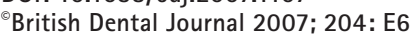

dentists are employed and remunerated. The latter include the employment of salaried dental practitioners in deprived and rural areas; expanding the use of mobile services; providing financial support to practices wishing to provide new or extended services; and rewarding general dental practitioners (GDPs) for their NHS commitment. There is also an increasing emphasis on the local planning and delivery of services in Scotland. ${ }^{4}$ NHS Health Boards are now taking a much more active role in securing access to dental services.

Access to health services has both supply and utilisation components which are considered in the context of perceived need, demand and oral health outcomes. ${ }^{5,6}$ Aspects of supply include the existence and availability of a service and whether systems are in place which permit service utilisation. ${ }^{7}$ One of the simplest and most widely used supply indicators in dentistry is the dentist to population $(\mathrm{D} / \mathrm{P})$ ratio, ${ }^{8}$ which provides a measure of the availability of services. ${ }^{9}$

A potential drawback of $\mathrm{D} / \mathrm{P}$ ratios is that they may mask significant variation in the availability of specific dental services such as NHS dental care. This is because they do not take into consideration part-time working, service productivity and the provision of private services. These factors are modelled in the recent workforce planning reports ${ }^{10,11}$ but the reports take a whole Scotland approach. The increasing devolution of planning to Health Boards means that local data are required. ISD Scotland provides information on the numbers of NHS dentists at a Health Board level, including whole time equivalent (WTE) values for dentists in the hospital, community and salaried general dental service (GDS) sectors. ${ }^{12}$ However, there are no WTE data for non-salaried GDS dentists who form the majority of dentists in most Health Boards. This creates a particular problem when measuring access to NHS primary dental care services at a Health Board level.

This study aims to address this deficit by providing information on the availability of NHS dental practitioners and primary care dental practitioners in Scottish Health Boards using $\mathrm{D} / \mathrm{P}$ ratios which are corrected for part time working, variation in service productivity and the provision of private services. 
Table 1 GDC dentist to population ratio of Health Board

\begin{tabular}{l|l|l|l}
\hline Area' & Population & $\begin{array}{l}\text { Number of dentists from GDC register } \\
(\mathrm{n}=2,815)\end{array}$ & Dentist/10,000 population ratio \\
\hline Argyll \& Clyde & 417,010 & 205 & 4.92 \\
Ayrshire \& Arran & 367,140 & 157 & 4.28 \\
Borders & 108,280 & 50 & 4.62 \\
Dumfries \& Galloway & 147,210 & 51 & 3.46 \\
Fife & 351,960 & 168 & 4.77 \\
Forth Valley & 279,680 & 133 & 4.76 \\
Grampian & 523,390 & 204 & 3.90 \\
Greater Glasgow & 866,370 & 648 & 7.48 \\
Highland & 209,080 & 127 & 6.07 \\
Lanarkshire & 553,440 & 248 & 4.48 \\
Lothian & 780,010 & 501 & 6.42 \\
Orkney & 19,310 & 12 & 6.21 \\
Shetland & 21,870 & 11 & 5.03 \\
Tayside & 386,550 & 289 & 7.48 \\
Western Isles & 26,100 & 11 & 4.21 \\
\hline 1. The research was conducted before the change of administrative boundaries in April 2006 & & \\
which resulted in the dissolution of Argyll \& Clyde. & & &
\end{tabular}

\section{METHOD}

\section{Study design}

A postal questionnaire survey was conducted of all dentists registered with the General Dental Council in 2004 at an address in Scotland. To ensure all dentists working in Scotland received a questionnaire, respondents were asked to provide details of colleagues who had not received a copy.

\section{Questionnaire}

The survey method employed a self-complete 39 item questionnaire which was developed to answer the objectives of the study. The design of the questionnaire was informed by evidence from a recent systematic review of factors increasing response rates to postal questionnaires ${ }^{13}$ and thus the questionnaire was kept as short as possible, the layout was clear and uncluttered and coloured ink was used. The questionnaire was piloted on a number of GDPs and reviewed by the Postgraduate Dental Dean for Scotland and consultants in dental public health both in Scotland and England to ensure that the questions were clear and unambiguous and that all the major issues had been examined. A small number of minor modifications to the wording of questions were made in advance of the main mailing.

The questionnaire included questions on field of dentistry, characteristics of working pattern and demographic characteristics of the respondents. Other sections investigated accessibility and accommodation in relation to primary care services, recruitment and retention, and attitudes towards incentives to treat patients under NHS arrangements. This paper will report only the findings in relation to the proportion of dentists working within the NHS across Health Boards. The findings relating to other aspects of the questionnaire are reported separately. ${ }^{14}$

\section{Administration of questionnaire}

The survey was conducted in accordance with evidence to maximise response rates. $^{13} \mathrm{~A}$ copy of the questionnaire, a personally signed covering letter explaining the purpose of the research and a reply-paid envelope were sent by first class post to each participant in June 2004, with two similar mail outs to non-respondents in July and August 2004. Each questionnaire was identifiable through a unique code.

\section{Data entry and analysis}

The coded responses were entered onto SPSS version 10.0. Data on working patterns were used to develop a model of the availability of whole time equivalent (WTE) NHS dental practitioners and WTE NHS primary dental care practitioners (including salaried and non-salaried GDS dentists and dentists working in the community dental service) within Scotland by Health Board area, taking into consideration population numbers.

\section{Modelling WTE NHS D/P ratios}

Firstly, the number of dentists providing NHS services in each Health Board $\left(\mathrm{N}^{\mathrm{NHS}}\right)$ was estimated using the following calculation:

\section{$\mathrm{N}^{\mathrm{NHS}}=(\mathrm{n} / \mathrm{r}) \mathrm{N}$}

where $n=$ number of dentists reporting that they provided NHS dental services for at least part of each week in the Health Board; $r=$ total number of respondents in the Health Board; and $\mathrm{N}=$ number of dentists on GDC register in the Health Board.

This assumes that dentists who provided NHS services and those who did not were equally likely to respond to the survey.

Secondly, a WTE score for each dentist was calculated in order to adjust for part-time working and time spent providing dental services privately. The WTE value was calculated by estimating that a WTE dentist spends 42.5 hours per week on NHS services (including associated administrative tasks) for 46 weeks per year, a total of 1,955 hours per year. This is the WTE calculation used in the Primary care dental workforce review in England ${ }^{8}$ and is used here for consistency. For each 
participant providing NHS dental services, the total number of hours he/she spent in delivering these services over the year was used to calculate his/her WTE score (WTE):

$\mathrm{WTE}=(\mathrm{h} \times \mathrm{w}) / 1,955$

where $\mathrm{h}=$ hours per week providing NHS services; and $\mathrm{w}=$ weeks per year providing NHS services.

Thirdly, the number of WTE NHS dentists in each Health Board was estimated using the mean WTE score for respondents in each Health Board. This assumes that non-respondents had the same working pattern as respondents within the Health Board. The WTE NHS D/P ratio in each Health Board (D/ $\left.\mathrm{P}^{\mathrm{WTE}}\right)$ was then calculated using population numbers for each Health Board:

$$
\mathrm{D} / \mathrm{P}^{\mathrm{WTE}}=\left(\mathrm{WTE}^{\text {mean }} \times \mathrm{N}^{\mathrm{NHS}}\right) / \mathrm{P}
$$

where $\mathrm{WTE}^{\text {mean }}=$ average WTE score for the Health Board; $\mathrm{N}^{\mathrm{NHS}}$ = estimated number of WTE dentists providing NHS services in the Health Board; and $\mathrm{P}=$ population of the Health Board.

The average salaried GDS practitioner provides approximately $40 \%$ of the treatments that the average non-salaried GDS dentist provides. ${ }^{10}$ To account for this, the WTE score of each salaried dentist working in GDS was reduced to 40\% of its original value. The mean WTE score for respondents in each Health Board was re-calculated and then used to determine the new WTE NHS D/P ratio in each Health Board as above.

The WTE NHS primary care D/P ratios were calculated using the same formulae. The number of respondents providing NHS primary dental care services in the Health Board was substituted for ' $n$ ' and the mean WTE values were calculated using WTE data for primary care dentists only. This assumes that the proportion of primary care dentists was the same in both the respondent and non-respondent groups within the Health
Board. It also assumes that the working patterns of primary dental care respondents and non-respondents were the same within the Health Board.

\section{Non-respondents}

Using information from the Dentists Register 2004, comparisons of the year of qualification and the area of residence between respondents and non-respondents were carried out using the Mann-Whitney U test and the Chi-square test. The findings were used to indicate non-response bias.

\section{Ethical approval}

Ethical approval for the study was granted by the King's College Hospital Research Ethics Committee (Ref: 04/Q0703/28).

\section{RESULTS}

Questionnaires were posted to a total of 2,852 dental practitioners, of whom 2,833 were taken from the Dentists Register $2004^{15}$ and 17 were identified by participants who returned their questionnaire and listed additional possible respondents. Two thousand one hundred and thirty-four completed questionnaires (74.8\%) were returned. A further 37 unopened questionnaires were returned (address not known/respondent died), giving a total response rate of 76.1\%.

\section{Description of the respondents}

Respondents were asked about their current working practices. One thousand seven hundred and seventy-three dentists (83.0\%) were providing NHS dental services for at least part of each week. Sixty-one dentists (2.9\%) were practising dentistry on a private basis only. Data for the private dentists and the remaining respondents were excluded from the analysis and are not reported.

Table 2 The process of estimating WTE NHS dentist to population ratio in each Health Board

\begin{tabular}{|c|c|c|c|c|c|c|}
\hline Area & $\begin{array}{l}\text { Number of den- } \\
\text { tists working for } \\
\text { NHS for at least } \\
\text { part of each week } \\
(n=1,773)\end{array}$ & $\begin{array}{l}\text { Total number of } \\
\text { respondents from } \\
\text { Health Board area } \\
(n=2,134)\end{array}$ & $\begin{array}{l}\text { Estimated number } \\
\text { of registered } \\
\text { dentists } \\
\text { providing } \\
\text { NHS services }\end{array}$ & $\begin{array}{l}\text { Estimated number } \\
\text { of WTE NHS } \\
\text { dentists }^{1}\end{array}$ & $\begin{array}{l}\text { Ratio of WTE } \\
\text { NHS dentists to } \\
10,000 \text { popula- } \\
\text { tion }\end{array}$ & $\begin{array}{l}\text { Ratio of WTE NHS } \\
\text { dentists to } 10,000 \\
\text { population (taking } \\
\text { into account lower } \\
\text { output of salaried } \\
\text { GDS dentists) }\end{array}$ \\
\hline Argyll \&t Clyde & 142 & 169 & 172.25 & 137.63 & 3.30 & 3.17 \\
\hline Ayrshire \& Arran & 119 & 135 & 138.39 & 108.21 & 2.95 & 2.91 \\
\hline Borders & 33 & 42 & 39.29 & 28.04 & 2.59 & 2.52 \\
\hline Dumfries \& G'way & 36 & 40 & 45.90 & 28.76 & 1.95 & 1.81 \\
\hline Fife & 119 & 146 & 136.93 & 108.26 & 3.08 & 3.05 \\
\hline Forth Valley & 99 & 118 & 111.58 & 93.28 & 3.34 & 3.20 \\
\hline Grampian & 155 & 184 & 171.85 & 111.51 & 2.13 & 2.00 \\
\hline Greater Glasgow & 355 & 426 & 54.00 & 432.70 & 4.99 & 4.88 \\
\hline Highland & 78 & 98 & 101.08 & 64.10 & 3.07 & 2.66 \\
\hline Lanarkshire & 164 & 181 & 224.71 & 191.34 & 3.46 & 3.40 \\
\hline Lothian & 293 & 362 & 405.51 & 283.77 & 3.64 & 3.51 \\
\hline Orkney & 8 & 9 & 10.67 & 8.53 & 4.42 & 3.00 \\
\hline Shetland & 8 & 8 & 11.00 & 9.25 & 4.23 & 2.60 \\
\hline Tayside & 155 & 206 & 217.45 & 171.68 & 4.44 & 4.33 \\
\hline Western Isles & 9 & 10 & 9.90 & 9.15 & 3.51 & 2.89 \\
\hline
\end{tabular}


Table 3 The process of estimating WTE NHS primary care dentist to population ratio in each Health Board

\begin{tabular}{|c|c|c|c|c|c|c|}
\hline Area & $\begin{array}{l}\text { Number of primary } \\
\text { care dentists }^{1} \\
\text { working for NHS } \\
\text { for at least part of } \\
\text { each week } \\
(n=1,577)\end{array}$ & $\begin{array}{l}\text { Total number } \\
\text { of respondents } \\
\text { from Health } \\
\text { Board area } \\
(n=2,134)\end{array}$ & $\begin{array}{l}\text { Estimated number } \\
\text { of primary care } \\
\text { dentists providing } \\
\text { NHS services }\end{array}$ & $\begin{array}{l}\text { Estimated } \\
\text { number of } \\
\text { WTE NHS } \\
\text { primary care } \\
\text { dentists }^{2}\end{array}$ & $\begin{array}{l}\text { Ratio of WTE } \\
\text { NHS primary } \\
\text { care dentists } \\
\text { to } 10,000 \\
\text { population }\end{array}$ & $\begin{array}{l}\text { Ratio of WTE NHS } \\
\text { primary care dentists } \\
\text { to } 10,000 \text { population } \\
\text { (taking into account } \\
\text { lower output of } \\
\text { salaried GDS dentists) }\end{array}$ \\
\hline Argyll \&t Clyde & 136 & 169 & 164.97 & 131.94 & 3.16 & 3.04 \\
\hline Ayrshire \&t Arran & 108 & 135 & 125.60 & 98.09 & 2.67 & 2.63 \\
\hline Borders & 30 & 42 & 35.71 & 24.33 & 2.25 & 2.18 \\
\hline Dumfries \& G'way & 34 & 40 & 43.35 & 26.73 & 1.82 & 1.68 \\
\hline Fife & 109 & 146 & 125.42 & 98.35 & 2.79 & 2.77 \\
\hline Forth Valley & 87 & 118 & 98.06 & 79.83 & 2.85 & 2.72 \\
\hline Grampian & 145 & 184 & 160.76 & 101.20 & 1.93 & 1.81 \\
\hline Highland & 286 & 426 & 435.04 & 340.81 & 3.93 & 3.82 \\
\hline Greater Glasgow & 71 & 98 & 92.01 & 56.03 & 2.68 & 2.28 \\
\hline Lanarkshire & 153 & 181 & 209.64 & 176.95 & 3.20 & 3.15 \\
\hline Lothian & 265 & 362 & 366.75 & 249.61 & 3.20 & 3.07 \\
\hline Orkney & 8 & 9 & 10.67 & 8.53 & 4.42 & 3.00 \\
\hline Shetland & 8 & 8 & 11.00 & 9.25 & 4.23 & 2.60 \\
\hline Tayside & 128 & 206 & 179.57 & 137.79 & 3.56 & 3.46 \\
\hline Western Isles & 9 & 10 & 9.90 & 9.15 & 3.51 & 2.89 \\
\hline
\end{tabular}

Of the dentists providing NHS dental services for at least part of each week, 1,032 (59.2\%) were male and the mean age of the respondents was 41.33 years $(S D=10.35)$. The vast majority of dentists $(1,358,80.8 \%)$ had no speciality. Participants were asked to indicate the Health Board area within which they provided NHS services for most of each week. There were more dentists in Greater Glasgow (355, 20.0\%) and Lothian (293, $16.5 \%$ ) than in the other Health Boards. Participants were also asked to indicate the sector of dentistry within which they provided NHS services for most of each week. Non-salaried dentists working in general dental practice provided the majority of NHS dental services in all Health Boards with the exception of Orkney, Shetland and the Western Isles, where salaried GDS dentists employed by Health Boards and dentists working for the community dental service provided the majority of primary care dental services. Hospital dentists were concentrated in Greater Glasgow, Lothian and Tayside.

\section{Dentist to population ratios}

Table 1 details the population numbers for each Health Board area $^{16}$ and the number of GDC registered dentists in each Health Board area. From these data the GDC D/P ratios were calculated. There were considerable differences between Health Boards; Greater Glasgow and Tayside had more than twice as many dentists as Dumfries \& Galloway per 10,000 population. The $\mathrm{D} / \mathrm{P}$ ratio for Scotland as a whole was 5.57 dentists per 10,000 population. This is slightly higher than the ratio of 5.21 dentists per 10,000 population for the United Kingdom. ${ }^{17}$

In order to provide more accurate information on NHS D/P ratios in each Health Board, the number of dentists providing NHS services for at least part of each week was estimated and adjusted to a WTE value using the formulae described above.
WTE NHS D/P ratios were then calculated for each Health Board (Table 2). For all the Health Boards, the WTE NHS D/P ratios were considerably lower than the GDC $\mathrm{D} / \mathrm{P}$ ratios. The ratios were subsequently adjusted for the lower output of salaried GDS dentists (Table 2). The latter adjustment impacted most in areas where a large proportion of the respondents were salaried GDS practitioners, such as Orkney, Shetland and the Western Isles.

For the whole of Scotland, the WTE NHS D/P ratio was 3.53 dentists per 10,000 population. When the reduced output of salaried GDS dentists was taken into account, the ratio dropped slightly to 3.40 dentists per 10,000 population.

Table 3 details the similar process of calculating the primary care WTE NHS D/P ratio for each Health Board. Figure 1 suggests that the ratios were relatively similar to those calculated for all WTE NHS dentists with the exception of Greater Glasgow and Tayside, reflecting the greater proportion of hospital dentists in those areas.

Irrespective of the method of calculation, Dumfries \&t Galloway and Grampian had the lowest, and Tayside and Greater Glasgow the highest D/P ratios (Fig. 1). However, there were considerable discrepancies in the relative positions of the other Health Boards. For example, the Highland Health Board had a much lower WTE NHS primary care D/P ratio, and Lanarkshire a much higher WTE NHS primary care D/P ratio than was suggested by the GDC D/P ratio. The adjusted ratios for Health Boards in the middle of the hierarchy of access were more similar than the corresponding GDC D/P ratios.

\section{Non-response bias}

In order to ascertain the degree of non-response bias in the findings, a comparison of response rate by Health Board areas 
was made. Response rates ranged from 66\% in Greater Glasgow to $91 \%$ in the Western Isles. The difference between the response rates by Health Board was significant (Chi-Square $=107.33, \mathrm{p}<0.0005)$. The difference in year of qualification between respondents and non-respondents was also tested using the Mann-Whitney U Test. The non-respondents had been qualified for an average of 16.3 years compared with an average of 18.2 years for the respondents. This difference was significant (Mann-Whitney $U=621677.5$, $p<0.001$ ).

The significant differences in response rates by Health Board and year of qualification between respondents and nonrespondents indicate that there may be some non-response bias in the findings.

\section{DISCUSSION}

This study has shown how simple ratios of registered dentists to population size can be misleading when assessing the availability of specific dental services such as NHS dental care. Firstly, there is a general over-estimation of the availability of NHS services, reflecting part-time working, the provision of private services and the number of dentists on the register who are retired or taking a career break. ${ }^{18,19}$ Secondly, GDC $\mathrm{D} / \mathrm{P}$ ratios may provide a misleading indication of the relative availability of NHS services between Health Boards. In this case, it appears that the adjusted ratios for Health Boards in the middle of the hierarchy of access were actually more similar than the corresponding GDC $\mathrm{D} / \mathrm{P}$ ratios. It is interesting to note that the relative positions of the Health Boards at the ends of the hierarchy of access did not change after adjustment. Thus, the re-modelling was most useful for assessing the relative availability of dental services in Health Boards located in the middle range of the hierarchy.

There were considerable differences in the availability of dental services between Dumfries \& Galloway and Grampian with the lowest D/P ratios, and Tayside and Greater Glasgow with the highest $\mathrm{D} / \mathrm{P}$ ratios. The study was conducted before legislation was passed to allow Health Boards to take a more active role in providing primary care dental services. It remains to be seen whether the twin track approach of national policy and incen- tives (such as increasing workforce numbers, access grants and remote area allowances) and local commissioning, will improve access in the Health Boards with the lowest D/P ratios. The study suggests that the vast majority of GDS dentists provide at least some NHS dental care. This may make it easier for the Scottish Executive and Health Boards to try to increase the proportion of NHS care provided than in other areas of the UK where the proportion of wholly private practice is greater. ${ }^{18} \mathrm{NHS}$ provision has improved in some areas through the employment of more salaried GDS dentists. However, since the output of salaried GDS practitioners is lower than their non-salaried peers, it may be more efficient for Health Boards to use other available incentives to encourage non-salaried GDS provision.

This paper describes a useful method for re-modelling D/P ratios to more accurately assess the availability of a specific service. However, there are a number of limitations which should be considered when interpreting the findings and applying the method in other research situations. The research was conducted at a time of widely publicised political debate on access to NHS services which may have affected the validity of the responses to questions about time spent on NHS and private services. The high response rate for the survey is very satisfactory ${ }^{20}$ and improves the validity of the findings. However, approximately $25 \%$ of dentists did not respond to the survey. During the modelling, it was assumed that non-respondents had the same working characteristics as respondents and this assumption may not be valid, particularly in Health Boards where the number of dentists was small. The analysis suggests that there may have been some non-response bias. Moreover, $3.6 \%$ of dentists failed to complete the section in the questionnaire on working hours, reducing the effective response rate.

Some dentists work in more than one field of dentistry and/ or more than one Health Board. In anticipation of this, dentists were simply asked to indicate which field of dentistry and in which Health Board they were currently providing NHS services for most of each week. A decision was taken by the research team not to investigate a respondent's second post because of the vastly increased length of the required questionnaire. Long questionnaires are shown to reduce response rates. ${ }^{13}$ This may

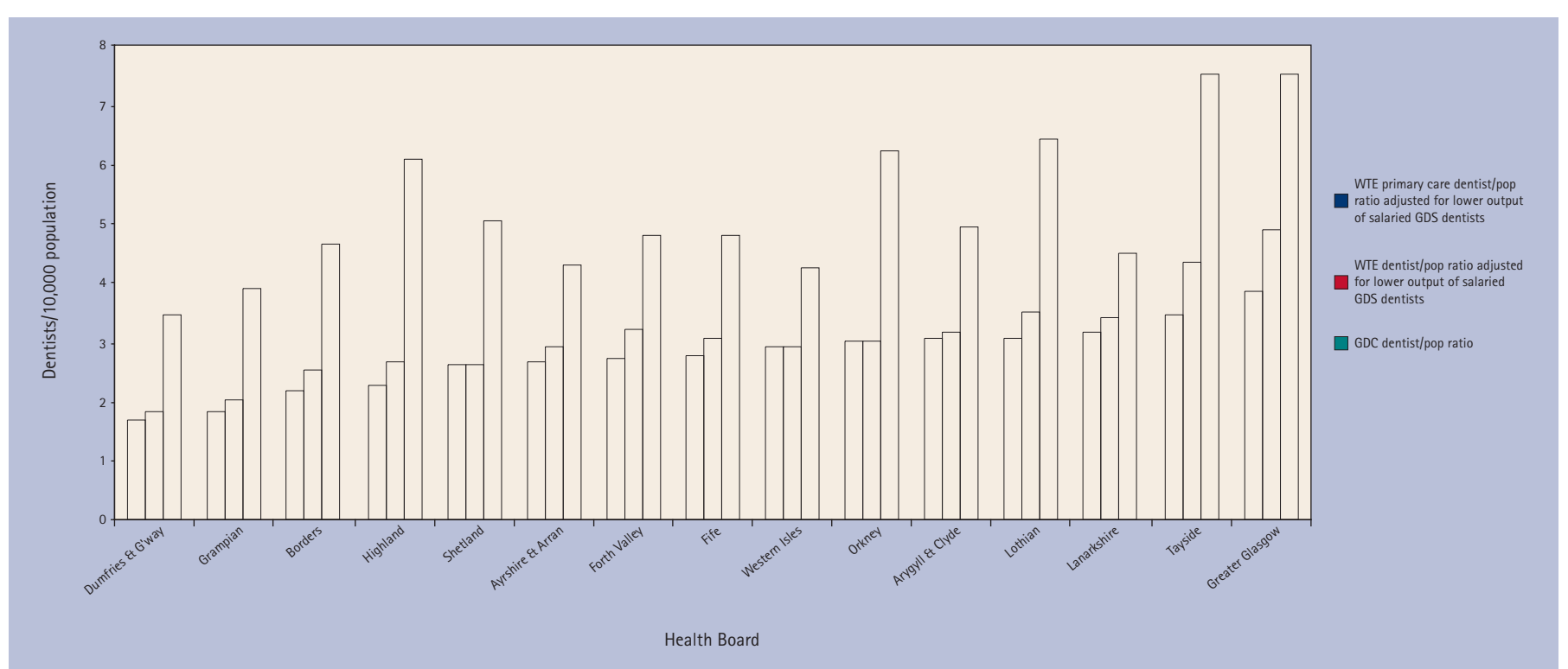

Fig. 1 Comparison between GDC dentist to population ratio, WTE dentist/population ratio (adjusted for lower output of salaried GDS dentists) and WTE primary care dentist to population ratio (adjusted for lower output of salaried GDS dentists) by Health Board 
have resulted in errors in the primary care $\mathrm{D} / \mathrm{P}$ ratios calculated. However, as only $2.7 \%$ of dentists combine hospital and primary care dentistry, ${ }^{11}$ the error is likely to be small. It is not known how many dentists work in more than one Health Board. The modelling also did not adjust for members of the population who use dental services in a different Health Board to their area of residence.

The modelling included an adjustment for the lower productivity of salaried GDS dentists but did not adjust for other variations in productivity such as the lower output of more recently qualified and/or older dentists. ${ }^{10}$ It also did not include the contribution of dental hygienists and therapists, who make up 14\% of the sum of dentists, hygienists and therapists in the UK. ${ }^{21}$

$\mathrm{D} / \mathrm{P}$ ratios are most meaningful when interpreted in the context of oral health need and demand for services. ${ }^{5}$ This study simply reported $\mathrm{D} / \mathrm{P}$ ratios because there are no published data on demand for dental services at a regional level. Assessing oral health need at a Health Board level is also difficult. There are DMFT data for 5-year-old and 11-year-old children but no corresponding regional oral health data for adults. Moreover, the D/P ratio is only one indicator of supply. A more valid assessment of access can be obtained by setting the $\mathrm{D} / \mathrm{P}$ ratios alongside other indicators of supply such as the proportion of dentists registering new patients, waiting times for treatment and disabled access etc. These indicators are reported elsewhere. ${ }^{14}$

Further investigation is required in order to provide a fuller picture of the availability of dental services. In particular, incorporating research consulting the Scottish population about their experiences of accessing dental care would be helpful in assessing demand for services and access problems at a Health Board level. More information on oral health need in adults at a Health Board level is required to be able to relate availability to need. The impact of dental care professionals on availability of dental services at a Health Board level could also be investigated.

The study was funded by the Scottish Parliament ref: 030104.

1. Health and Social Care (Community Health and Standards) Act 2003. Available at: http://www.opsi.gov.uk/ACTS/acts2003/20030043.htm [Accessed 4.9.06]
2. World Health Organization. Oral health services. Available at: http://www.who. int/oral health/action/services/en/index.html [Accessed 4.9.06]

3. Scottish Executive. An action plan for improving oral health and modernising NHS dental services in Scotland. Edinburgh: Scottish Executive Health Department, 2005.

4. Scottish Executive. Delivering for health. Edinburgh: Scottish Executive, 2005. Available at: http://www.scotland.gov.uk/Publications/2005/11/02102635/26356 [Accessed 4.9.06]

5. Andersen R. Revisiting the behavioural model and access to medical care: does it matter? J Health Soc Behav 1995; 36: 1-10.

6. Gibson B. Access to dental services. In Gulliford M, Morgan M (eds). Access to health care. London: Routledge, 2003.

7. Starfield B. Primary care. Concept, evaluation and policy. New York: Oxford University Press, 1992.

8. Department of Health. Report of the primary care dental workforce review. London: Department of Health, 2004.

9. Penchansky $R_{1}$ Thomas J W. The concept of access: definition and relationship to consumer satisfaction. Med Care 1981; 1: 127-140.

10. NHS Education for Scotland/ISD Scotland. Workforce planning for dentistry in Scotland. Edinburgh: NES Scotland/ISD Scotland, 2004. Available at: http:// www.nes.scot.nhs.uk/documents/publications/classa/Workforce_planning.pdf [Accessed 8.8.07]

11. NHS Education for Scotland/ISD Scotland. An update on the analysis and modelling of dental workforce in Scotland. Edinburgh: NES Scotland/ISD Scotland, 2006. Available at: http://www.isdscotland.org/isd/files/Dentistry\%20Analysis\% 202006.pdf [Accessed 31.8.06]

12. ISD Scotland. Table D2: general dental, community \& hospital dentists by NHS Board. Available at: http://www.isdscotland.org/isd/files/D2_by_NHS_Board_ Sep05.xls [Accessed 4.9.06]

13. Edwards $\mathrm{P}$, Roberts I, Clarke $\mathrm{M}$ et al. Increasing response rates to postal questionnaires: systematic review. Br Med J 2002; 324: 1183-1192.

14. Newton J T, Williams A C, Bower E J. Access to dental health services in Scotland. Edinburgh: Scottish Parliament, 2005. Available at: http://www.scottish. parliament.uk/business/committees/health/reports-05/her05-research-00.htm [Accessed 29.1.07]

15. General Dental Council. Dentists Register 2004. London: General Dental Council, 2004.

16. General Register Office for Scotland. 2003 mid-year estimate for Scotland's Council and Health Board areas. Available at: http://www.gro-scotland.gov. uk/grosweb/grosweb.nsf/pages/file11/\$file/03mid-year-estimates-table3.xls [Accessed 7.9.04]

17. Kravitz A, Treasure E. EU manual of dental practice. Brussels: The Liaison Committee of the Dental Associations of the European Union, 2004. Available at: http://www.bda.org/education/docs/EU\%20Manual\%201\%20June\%202004. pdf [Accessed 8.8.07]

18. Buck D, Newton J T. The privatisation of NHS dentistry? A national snapshot of general dental practitioners. Br Dent J 2001; 190: 115-118.

19. Newton J T, Buck D, Gibbons D. Workforce planning in dentistry: the impact of shorter and more varied career patterns. Community Dent Health 2001; 18: 236-241.

20. Dillman D. Mail and internet surveys: the tailored design method. New York: Wiley, 2000.

21. General Dental Council. 2005 annual report. London: General Dental Council, 2006. 